\title{
A Pragmatic Approach to Evidence-Based Public Health Policy
}

\author{
Anton Lager*,1, Jennie Bacchus Hertzman ${ }^{1}$ and Karin Guldbrandsson ${ }^{2}$ \\ ${ }^{I}$ Centre for Health Equity Studies (CHESS), Stockholm University/Karolinska Institutet, Stockholm, Sweden \\ ${ }^{2}$ Department for Public Health Sciences, Karolinska Institutet, Stockholm, Sweden.
}

\begin{abstract}
The evidence-based approach is a means to improve the quality, safety and cost-effectiveness of the public sector as a whole, not only the health service. But to be successful, the evidence-based approach needs to be restricted to the stage of the policy process where it really can make a contribution; namely in the choice of intervention. In the policy process phase that precedes the choice of intervention, i.e. the problem formulation phase, there can by definition be no "evidence" available, since no controlled trials can ever prove that one problem is bigger than another. Further, the policy process phase following the choice of intervention, i.e. the implementation phase, is to date still restricted to research of weaker design and the policy makers need to consider input from many different sources also here. A pragmatic approach, focusing the choice of intervention phase of the policy process, has proved successful in the dissemination of an evidencebased policy for parenting support in Sweden.
\end{abstract}

Keyword: Policy, Evidence, Public Health, Guidelines, Recommendations, GRADE.

\section{INTRODUCTION}

Archibald Cochrane, the pioneer of evidence-based medicine, had watched fellow war prisoners during World War II get sick and then recover almost entirely without access to healthcare. He consequently came to suspect that much of what was being done by the health services at the time was pointless or even harmful, and that most successful outcomes could be attributed to the "recuperative powers of the human body" [1]. This was coupled with the insight that much research is misleading because it has a too weak design. His radical suggestion was that healthcare should be organised around the few treatments that were either proven to be effective in randomised controlled trials, RCTs, or had such an obvious and direct effect on survival that experiments were not needed.

The first Cochrane Centre, opened in Oxford, United Kingdom, in 1992, and with initial funding from, among others, the Swedish Council on Health Technology Assessment, later developed into the Cochrane Collaboration [2]. Medline indexed four articles with "evidence-based" in the title published that year - but 88 articles published in the year of 1995, 631 articles published in the year 2000 and 1405 articles published in the year of 2010 [3].

Today, the evidence-based approach is expanding both horizontally and vertically. The horizontal expansion, from health services to other parts of the public sector - such as education, crime and justice, social welfare, transportation or urban renewal policies $[4,5]$ - is welcome. Many current public health or social work interventions, for example, are likely to be ineffective or even harmful [6]. In the year of

*Address correspondence to this author at CHESS, Stockholm University, SE-106 91 Stockholm, Sweden; Tel: +46703142514; Fax: +468162600;

E-mail: anton.lager@chess.su.se
2000 the international research network Campbell Collaboration, an analogue to the Cochrane Collaboration in medicine, was created. The Campbell Collaboration has the mission to "help people make well-informed decisions by preparing, maintaining and disseminating systematic reviews in education, crime and justice, and social welfare" [4]. Although a major driver of the evidence-based approach is likely to be the quickly expanding evidence-base itself, another factor that might have had relevance is that policy makers, in order to make efficient decisions, are forced to deal with an increased complexity in society [5].

However, the evidence-based approach has recently also been expanding vertically; it has gone from being applied exclusively to interventions or treatments, to embracing every aspect of the policy process. About half of the articles with "evidence-based policy" (EBP) in the title, that has ever been published and indexed in Google Scholar (2012), are published after the year of 2006. Policy makers are now urged to look for "evidence" during the agenda setting stage of the policy process (to answer questions such as: what are the major problems?), during the decision-making stage of the process (what action should be taken?), as well as during implementation (how should the chosen action be implemented?) $[7,8]$.

The problem with this vertical expansion, and the focus of this paper, is that the "evidence" which is available in the problem formulation stage of the policy process is inevitably weak and that only a few per cent of studies in implementation research are experimental [9]. To claim that these two phases can still be "evidence-based" may undermine the chances of the evidence-based approach adding value during the stage of the policy process where it can be really useful, namely in the decision-making stage. Further, even in this phase, the evidence-based approach has natural limits, either 
because evidence-based interventions are not available for the specific problem that has to be addressed or because the external validity of available studies can be questioned. This has also to be acknowledged, in order for the evidence-based approach to retain credibility.

In this paper the evidence-based approach is discussed in relation to each of these three stages of the policy process. A more focused and pragmatic approach, that has shown to be successful in spreading the use of evidence-based parenting support methods in Sweden, is suggested.

\section{“EVIDENCE-BASED" PROBLEM FORMULATION}

The vertically expanded evidence-based policy approach urges decision-makers to look for evidence when identifying and prioritising problem areas. This has been called "Evidence Type 1" [7]. It can indeed be argued that utilising research is better than relying on personal experience and intuition. However, the mere fact that something has been quantified and researched does not necessarily mean that it should be prioritised. Moreover, even in an ideal situation where every fact has been clarified by research - persons with different values will still attach differing degrees of importance to the issue in question. Hence, choices in this phase will always reflect personal and political values. If we dress up the basis for choices in this phase as "evidence" there is a risk that we will move from evidence-based policy to "policy-based evidence" [10].

A main issue is that the scientific support for something being a problem is typically based on observational data. These data have several inherent weaknesses which evidence from experimental studies on interventions are more free from, most importantly the risk of reverse causality and confounding [11]. The exponential increase in the number of published observational studies, and the increasing usage of complex statistical modelling, are unfortunately no magic solutions to this problem. Thus, talking of "evidence" (rather than "research") at the problem formulation stage of the policy-making process is misleading and risks undermining efforts to convince policymakers at the decision-making stage of the process, where real evidence based on experimental studies in fact could be available.

An example which illustrates both the contribution and the limitations of research in the problem-formulation phase of the policy process is the disability-adjusted life-years-lost (DALY) approach [12] which gives each health problem a weight according to its severity. This weight is then multiplied by the cumulative prevalence of the problem. According to these calculations, living two years with clinical depression is equivalent to dying one year prematurely. By carrying out the same procedure for all known diseases, more rational lists of disease burden can definitely be produced. By using our knowledge of risk-factors we can produce similar lists for the determinants of disease.

The DALY approach has helped to put mental health problems, which tend not to be fatal, at the very top of the list of public health problems and tobacco use at the top of the list of causes of disease. In this way, DALY can arguably help make the decision process clearer and more rational. However, there is no evidence; no "proof" that living with untreated depression for two years corresponds to dying one year prematurely. The weight attributed to it is not objective and will inevitably reflect certain values and assumptions [13]. In addition, some issues will always be missing from the DALY-lists, such as future ways of classifying diseases and new ways of thinking about determinants. Thus, approaches such as the DALY should be thought of as ways to rationalise and clarify reasoning but not as "evidence".

\section{EVIDENCE-BASED DECISION MAKING}

The decision-making phase of the policy process is where the real strengths of the evidence-based approach lie. Some new EBP-initiatives, for example in public health and social work, have also resisted the vertical expansion and stayed focused on this stage of the process $[14,15]$. The evidencebased approach can, and should, encourage policymakers to consider new interventions that have support in randomized controlled trials (see the example from Sweden below). In addition, another important contribution of the evidencebased approach comes from evidence of the harmful effects of certain current interventions [6].

Yet, even in the decision making part of the process, there are some clear and important limits to the evidencebased approach. After all, also when there is high quality evidence available, it ultimately should fall to the popularlyelected representatives to take the decisions [16, 17]. In addition, sometimes no evidence-based intervention is available for the problem in question, and in these case only weak guidelines or recommendations can follow [18].

Even in favourable situations when there is an evidencebase of RCTs, this base will seldom be perfect, i.e. it might emanate from studies of other settings or other populations. In fact, if one moves outside the health services and beyond the USA or Great Britain, it is even highly unlikely that there will be two randomized controlled trials of the exact intervention in question, carried out by independent research groups, published in peer-reviewed journals, and undertaken in the exact country and setting at hand. Thus, there will always be more or less problems of generalising from the evidence-base that do exist. This should be clearly acknowledged.

\section{“EVIDENCE-BASED" IMPLEMENTATION}

There is to date no sufficient evidence base of randomised controlled trials on how to implement specific interventions $[19,20]$. For this reason, talking about "evidence" here, is again misleading and could be counterproductive. Further, the trials, or systematic reviews, of the effects of interventions themselves are seldom useful in the implementation process [21-23].

Research can certainly help in implementation, for example, Durlak and DuPre have in a systematic literature review identified 23 factors affecting implementation [24]. These factors still have, however, to be supported by experimental studies. As long as most research in this area is not of an experimental design [9], researchers should arguably not oppose the policy makers way of taking many different views into account here. After all, the experience of a local official with initiated organizational knowledge might prove 
to be at least as important as the experience of a researcher when coming to implementation in practice.

Thus, the evidence-based approach needs to stay focused on the choice of intervention in the decision-making phase and be toned down in the problem formulation and implementation phases of the policy process. In Sweden, evidence-based parenting support programs have been successfully implemented in this way for the past ten years, ever since the government in office commissioned a report from the Swedish National Institute of Public Health, a centre reviewing the evidence for interventions in public health.

The report proposed three types of evidence-based programs: attachment programs for parents with infants, parent training programs for parents with pre-schoolers and drugpreventive programs for parents with adolescents [25]. A list of evidence-based methods, highlighting programs that had already been adapted to Swedish conditions, was made available to relevant actors, mainly municipalities and county councils which had identified a need for interventions. No detailed recommendations about how to implement the parenting support programs were given.

Instead the implementation was drivean locally, resulting in parenting support programs implemented in the social services, child psychiatry units and child health care centres; in private and public preschools and schools; by nongovernmental organizations and even by corporations for their employees.

The follow-up studies suggest that the dissemination has been largely successful for all three types of program. During the late 1990s there was only occasional use of all three types of programs. In the late 2000s, however, attachment programs were used in 15 per cent of all child health care centres [26], parent training programs in around 56 per cent of all municipalities and drug preventive programs in around 80 per cent of municipalities.

Interestingly, the dissemination was quick for the parenting training programs for which there was no given specific arena, while it was slower for the evidence-based attachment programs, which had to replace existing non-evidence-based methods at child health care centres.

Hopefully, the Swedish example indicates that the horizontal expansion of the evidence-based approach to arenas outside the health care sector might become successful, and thus that also these sectors may move closer to Cochrane's vision of a safe and cost-effective organisation focused on a number of proven beneficial activities [1].

\section{CONCLUSION}

It is here suggested that the evidence-based approach should be focused on the decision-making phase and toned down in the problem formulation and implementation phases of the policy process.

\section{CONFLICTS OF INTEREST}

The authors confirm that this article content has no conflicts of interest.

\section{ACKNOWLEDGEMENTS}

The paper was based on an idea by AL. It was drafted by $\mathrm{AL}$ and revised by JBH and KG. The authors thank Nina Rehnqvist, chair of the board at Swedish Council on Health Technology Assessment, and Sven Bremberg, responsible for a Swedish national commission on parenting support, for valuable comments on earlier drafts.

\section{REFERENCES}

[1] Cochrane AL. Effectiveness and efficiency: random reflections on health services. Repr. ed. Lon R Soc Med 1999; 12: 1931-71.

[2] Cochrane Collaboration. History: Cochrane Collaboration; 2012. Available from: http://www.cochrane.org/about-us/history [cited 2012 Sept 6].

[3] U.S. National library of medicine. PubMed: U.S. National Library of Medicine; 2012. Available from: http://www.ncbi.nlm.nih.gov/ pubmed [cited 2012 Sept 6].

[4] Campbell Collaboration. About us: Campbell Collaboration; 2012. Available from: http://www.campbellcollaboration.org/about_us/ [cited 2012 July 21].

[5] Davies HTO, Nutley S, Smith PC. What works? Evidence-based policy and practice in public services. Bristol: Policy Press 2000.

[6] Macintyre S, Chalmers I, Horton R, Smith R. Using evidence to inform health policy: case study. BMJ 2001; 322(7280): 222-5.

[7] Brownson RC, Fielding JE, Maylahn CM. Evidence-based public health: a fundamental concept for public health practice. Annu Rev Public Health 2009; 30: 175-201.

[8] Fielding JE, Briss PA. Promoting evidence-based public health policy: can we have better evidence and more action? Health Aff (Millwood) 2006; 25(4): 969-78.

[9] Fixsen D, Naoom S, Blase K, Friedman R, Wallace F. Implementation research: a synthesis of the literature. Tampa, Florida: University of South Florida, Louis de la Parte Florida Mental Health Institute, National Implementation Research Network 2005.

[10] Marmot MG. Evidence based policy or policy based evidence? BMJ 2004; 328(7445): 906-7.

[11] Rosen L, Manor O, Engelhard D, Zucker D. In defense of the randomized controlled trial for health promotion research. Am J Public Health 2006; 96(7): 1181-6.

[12] World Bank. Investing in health. NY: Oxford University Press 1993.

[13] Arnesen T, Nord E. The value of DALY life: problems with ethics and validity of disability adjusted life years. BMJ 1999; 319(7222): 1423-5.

[14] Davies P, Boruch R. The Campbell Collaboration. Does for public policy what cochrane does for health. BMJ 2001; 323(7308): 294 5 .

[15] Waters E, Doyle J. Evidence-based public health: Cochrane update. J Public Health Med 2003; 25(1): 72-5.

[16] Muir GJA. Evidence based policy making. BMJ 2004; 329 (7473): 988-9.

[17] Young SP. Evidence of democracy: the relationship between evidence-based policy and democratic government. J Public Adm Policy Res 2011;3(1): 19-27.

[18] Guyatt GH, Oxman AD, Vist GE, et al. GRADE: an emerging consensus on rating quality of evidence and strength of recommendations. BMJ 2008: 336(7650): 924-6.

[19] Chamberlain P, Brown CH, Saldana L, et al. Engaging and recruiting counties in an experiment on implementing evidence-based practice in California. Adm Policy Ment Health 2008; 35(4): 25060.

[20] Grimshaw JM, Eccles MP, Lavis JN, Hill SJ, Squires JE. Knowledge translation of research findings. Implement Sci 2012; 7(1): 50 .

[21] Ellis P, Robinson P, Ciliska D, et al. A systematic review of studies evaluating diffusion and dissemination of selected cancer control interventions. Health Psychol 2005; 24(5): 488-500.

[22] Thompson DS, Estabrooks CA, Scott-Findlay S, Moore K, Wallin L. Interventions aimed at increasing research use in nursing: a systematic review. Implement Sci 2007; 2: 15.

[23] Hanney S, Mugford M, Grant J, Buxton M. Assessing the benefits of health research: lessons from research into the use of antenatal 
corticosteroids for the prevention of neonatal respiratory distress syndrome. Soc Sci Med 2005; 60(5): 937-47.

[24] Durlak JA, DuPre EP. Implementation matters: a review of research on the influence of implementation on program outcomes and the factors affecting implementation. Am J Community Psychol 2008; 41(3-4): 327-50.
[25] Bremberg s (Ed). New tools for Parents proposals for new forms of parents support. Stockholm: Swedish National Institute of Public Health 2006.

[26] Wallby T. Föräldrastöd på BVC: en nationell kartläggning. In: Sarkadi A, Ed. Föräldrastöd i Sverige idag. Östersund \& Uppsala: Swedish National Institute of Public Health \& Uppsala County Council 2009.

(C) Lager et al.; Licensee Bentham Open.

This is an open access article licensed under the terms of the Creative Commons Attribution Non-Commercial License (http://creativecommons.org/licenses/ by-nc/3.0/) which permits unrestricted, non-commercial use, distribution and reproduction in any medium, provided the work is properly cited. 